\title{
Micro-Pop-In Issues in Nanoscale Contact Deformation Resistance of Tooth Enamel
}

\author{
Nilormi Biswas, ${ }^{1}$ Arjun Dey, ${ }^{1,2}$ and Anoop Kumar Mukhopadhyay ${ }^{1}$ \\ ${ }^{1}$ Mechanical Property Evaluation Section, CSIR-Central Glass and Ceramic Research Institute, Kolkata 700 032, India \\ ${ }^{2}$ Thermal Systems Group, ISRO Satellite Centre, Vimanapura, Bangalore 560 017, India
}

Correspondence should be addressed to Anoop Kumar Mukhopadhyay; anoopmukherjee@cgcri.res.in

Received 14 August 2012; Accepted 6 September 2012

Academic Editors: J.-Y. Cognard and N. Dunne

Copyright (c) 2013 Nilormi Biswas et al. This is an open access article distributed under the Creative Commons Attribution License, which permits unrestricted use, distribution, and reproduction in any medium, provided the original work is properly cited.

\begin{abstract}
Human tooth enamel is a natural nanocomposite with a hierarchical structural architecture that spans from macroscale to nanoscale. Thus it offers the unique opportunity to study the physics of deformation at the nanoscale in a controlled manner using the novel nanoindentation technique. In spite of the wealth of literature, however, the information about the effect of loading rate on the nanoindentation behavior of human tooth enamel is far from being significant. Therefore, the major objective of the present work was to study the loading rate effect on nanoindentation behavior of enamel with a view to improve our understanding that could be used for development of better bioinspired synthetic structures for functional as well as biomedical utilities. The nanoindentation experiments were conducted at loading rates in the range of $10^{3}$ to $\sim 0.3 \times 10^{6} \mu \mathrm{N} \cdot \mathrm{s}^{-1}$ at peak load of $10^{5} \mu \mathrm{N}$ at room temperature with a Berkovich tip on the longitudinal section from a freshly extracted premolar tooth enamel surface from a 65-year-old Indian male. To the best of our knowledge here we report for the first time the experimental observation of the increase in intrinsic resistance against contact-induced deformation at the nanoscale with the loading rate applied to the enamel surface. The results were explained by considering the microstructural details and the shear stress underneath the nanoindenter.
\end{abstract}

\section{Introduction}

The nanocomposite structure of the human tooth enamel provides a unique opportunity to study the physics of deformation during the nanoscale contact events because it consists of hydroxyapatite (HAP) nanocrystals embedded in an organic-protein matrix with hierarchical structures from macrostructure to microstructure to sub-microstructure to nanostructure to sub-nanostructure [1-3]. The tooth enamel can survive normally up to even a billion contacts between themselves. The tooth enamel has nanohardness $(H)$ in the range of 3 to $5 \mathrm{GPa}$ [4-10]. The indenter shape [5], teeth type [6], location [7, 8], degree of biomineralization $[9,10]$, and depth of indentation [11] can affect the data. The HAP single crystals have nanohardness higher than that of enamel [12]. The tooth makes various mastications during all oral cavity movements. All these contact-induced events that determine the life of the enamel are the sum total of a multitude of nanoscale contact events under a wide variety of loading rates which have not been studied in significant details [112]. Neither the role of micro-pop-in nor micro-pop-out issues during nanoscale contact events happening under different loading rates in influencing the nanoscale contact resistance has been discussed in the available literature on tooth enamel [1-12]. Therefore the major objective of the present work is the study of the loading rate effect on nanoindentation behavior of enamel for further utilization of bioinspired synthetic structures for both biomedical and functional applications.

\section{Experimental}

The polished $\left(R_{a} \sim 0.25 \mu \mathrm{m}\right)$ longitudinal section from a freshly extracted premolar tooth enamel surface from a 65year-old Indian male individual was the sample. The nanoindentation experiments (Fischerscope H100-XYp; Fischer, Switzerland) were conducted at a constant load of $10^{5} \mu \mathrm{N}$ 


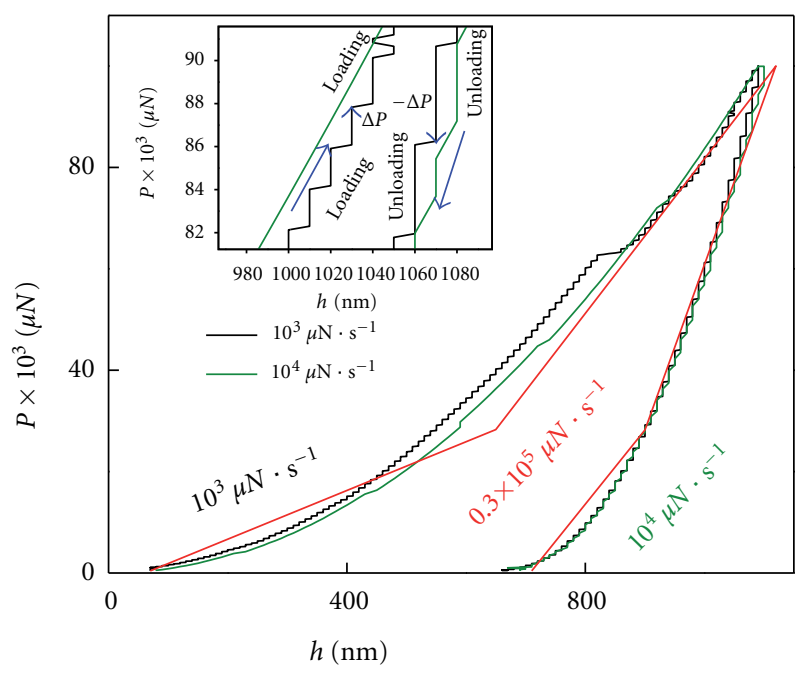

FIgURE 1: Load $(P)$-depth $(h)$ plots at different loading rates (inset: exploded views of the loading and unloading parts).

at room temperature with a Berkovich tip of $150 \mathrm{~nm}$ radius. The well-known Oliver and Pharr method [13] was used to evaluate the nanohardness $(H)$ and Young's modulus $(E)$ data from the load $(P)$ versus depth $(h)$ plots. By varying the loading times the loading rates $\dot{P}$ were varied in the range of $10^{3}$ to $\sim 0.3 \times 10^{6} \mu \mathrm{N} \cdot \mathrm{s}^{-1}$. Further details are given elsewhere [14].

\section{Results and Discussions}

Figure 1 exhibits the $P-h$ plots at various loading rates and the inset their exploded views. The prominent signatures of the initiation of nanoscale plasticity events during the nanoindentation experiments are borne by the large number of multiple "micr-pop-in" and "micro-pop-out" events those occurred (inset, Figure 1) during the loading and unloading cycles. Similar pop-in behavior has been observed for bulk metallic glasses [15-17], sapphire [18], GaN [19] and $\mathrm{ZnO}$ [20], glass [21, 22], and polycrystalline alumina [23, 24].

The inset of Figure 1 also shows that the load increment $(\Delta P)$ at which two consecutive "micro-pop-in" events (say, 1, 2) happened during the loading cycle were not the same as the load decrement $(-\Delta P)$ at which two consecutive "micropop-out" (say, 1, 2) occurred during the unloading cycle. The number of "micro-pop-in" and "micro-pop-out" events occurred much more at $10^{3}$ than at $10^{4} \mu \mathrm{N} \cdot \mathrm{s}^{-1}$ loading rates, Figure 1 (inset). Each discrete jump in the $P$ - $h$ plots marks a critical load $P_{c}$ and the corresponding depth is a critical depth $\left(h_{c}\right)$ at which the nanoscale plasticity events had just initiated. The data of Figure 2 confirms that both $P_{c}$ and the corresponding maximum shear stresses $\left(\tau_{\max }\right.$ [25-28] $\sim 10-30 \mathrm{GPa}$ ) exhibited positive power law dependencies on the loading rate.

This data proved beyond doubt that the critical load for initiation of plasticity at the nanoscale of the enamel nanocomposite was actually enhanced with increase in $\dot{P}$. For the enamel nanocomposite, the critical load basically

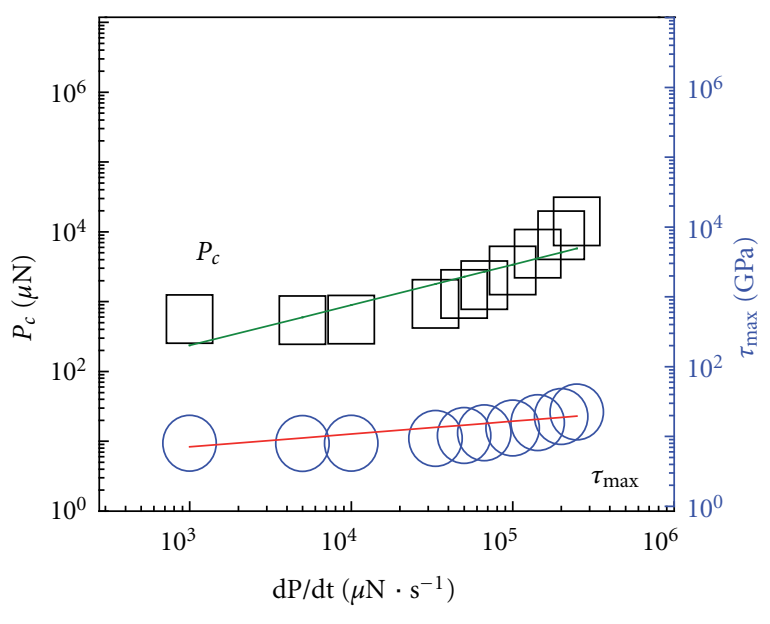

Figure 2: Variations of the critical load $\left(P_{c}\right)$ and maximum shear stress $\left(\tau_{\max }\right)$ active just underneath the nanoindenter as a function of the loading rates $(\mathrm{dP} / \mathrm{dt})$. The solid lines indicate the corresponding power law fits.

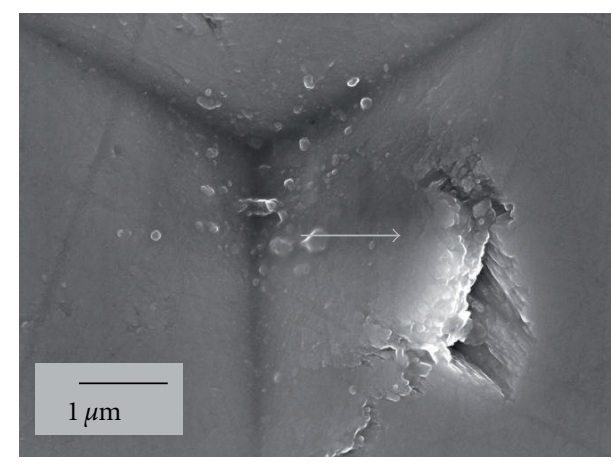

FIGURE 3: FESEM photomicrograph of shear-induced microfracture (marked by hollow white arrow) at the vicinity of a typical nanoindentation made at $10,000 \mu \mathrm{N} \cdot \mathrm{s}^{-1}$ loading rate in the tooth enamel.

signifies the minimum force that is required to just overcome the intrinsic resistance against contact-induced deformation. Thus, the present data is the very first experimental observation that the intrinsic contact deformation resistance of enamel nanocomposites increased with $\dot{P}$. To the best of our knowledge, such observation is the first. This aspect shall be discussed in detail later.

The value of $\tau_{\max }$ was much higher than $\tau_{\text {theor }} \sim 3-6 \mathrm{GPa}$ which implies that nanoscale plasticity events $[27,28]$, for example, shear-induced microfracture, were expected in the vicinity of the nanoindented enamel nanocomposite, as was indeed observed (Figure 3). The depth increment $\left(\Delta h=h_{c_{1}}-h_{c_{2}}\right)$ (at which two consecutive "micro-pop-in events" (say, 1, 2) had happened) exhibited empirical power law dependencies with positive exponents on the corresponding load increment $(\Delta P)$, Figure 4 and also on $P_{c}$ (inset, Figure 4).

Similarly $h_{c}$ displayed a positive empirical power law dependence on $P_{c}$ of the enamel nanocomposite, Figure 5. The power law dependence of depth $(h)$ on load $(P)$ during 


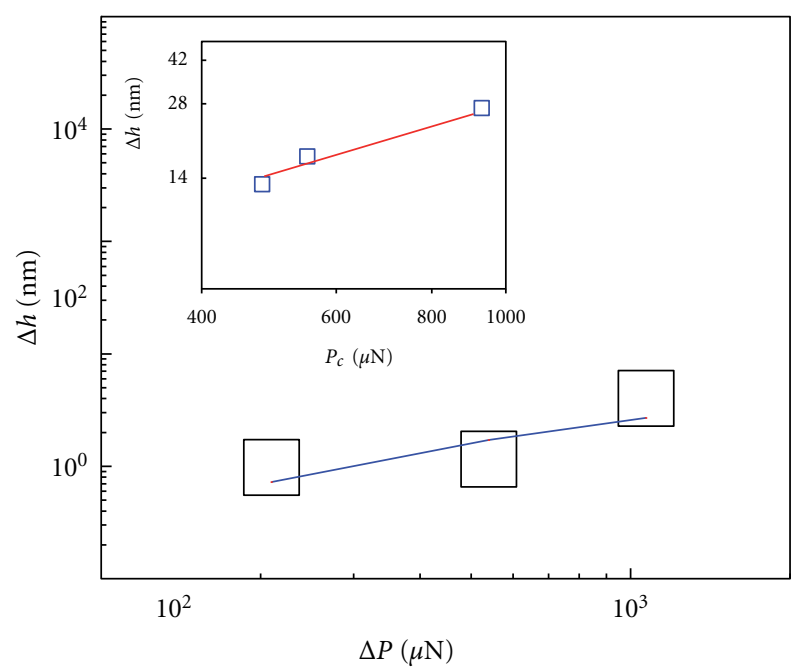

FIgURE 4: The dependencies of depth increment $(\Delta h)$ and decrement $(-\Delta h)$ on the corresponding load increment $(\Delta P)$ and decrement $(-\Delta P)$ at which two consecutive nanoscale plasticity events had occurred during the loading and unloading cycles (inset), respectively. The solid lines indicate the corresponding power law fits.

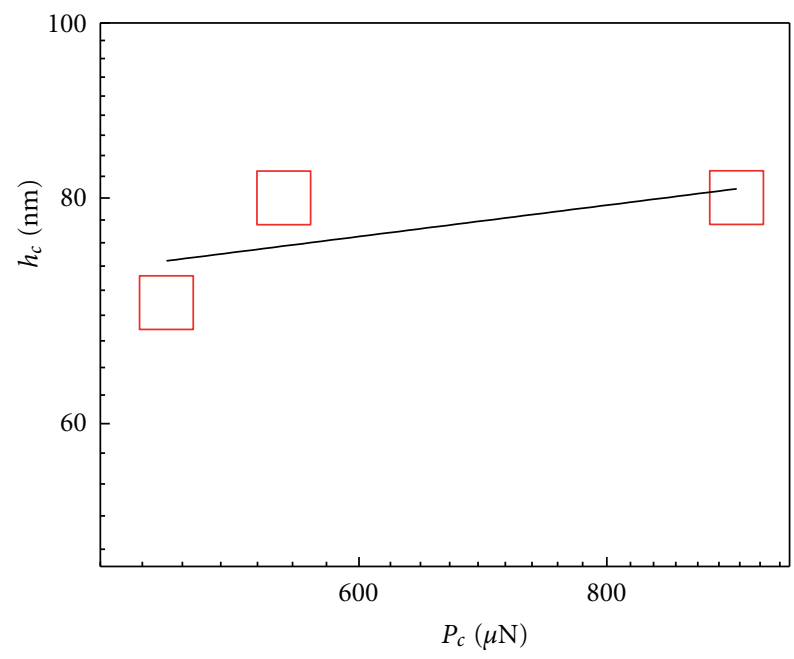

FIgURE 5: The dependence of the critical depth $\left(h_{c}\right)$ on the critical load $\left(P_{c}\right)$ in tooth enamel. The solid line indicates the corresponding power law fits.

the loading cycle of the nanoindentation experiments can be explained in accordance with two recent models $[29,30]$. The experimental $P$ - $h$ data presented in Figure 6 confirmed the generic nature of such dependencies of $h$ on $P$ for loading rates of $10^{3}$ to $0.3 \times 10^{6} \mu \mathrm{N} \cdot \mathrm{s}^{-1}$.

Further, both $\Delta h$ and depth decrement $\left(-\Delta h=h_{c_{1}}-h_{c_{2}}\right)$ showed empirical power law dependencies on the loading rate with positive exponents (Figure 7). The empirical power law dependence of $\Delta h$ on $\dot{P}$ was in accordance with the theoretical prediction $h \propto \dot{P}^{\alpha}$ of a recent model [30] where $\alpha$ was an empirical constant. The model [30] required that at all loading rates $\dot{h}$ were effectively constant with respect to time. This condition was indeed true (Figure 8) for the present

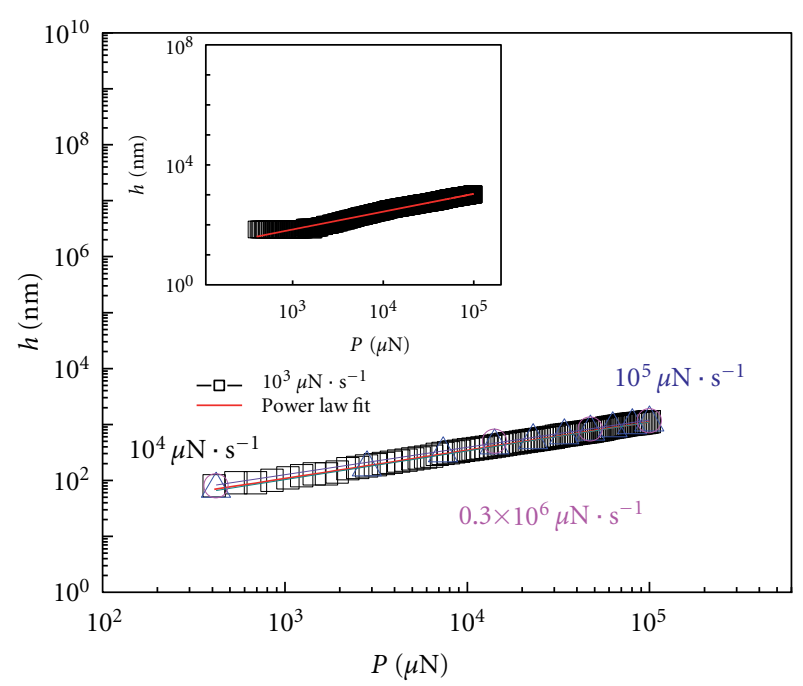

FIgURE 6: The experimental data on dependence of the instantaneous nanoindentation depth $(h)$ on the instantaneous nanoindentation load $(P)$ obtained during the loading cycles at different loading rates of $0.3 \times 10^{6}, 10^{5}, 10^{4}$, and $10^{3} \mu \mathrm{N} \cdot \mathrm{s}^{-1}$ (inset of Figure $6)$. The solid lines indicate the corresponding power law fits.

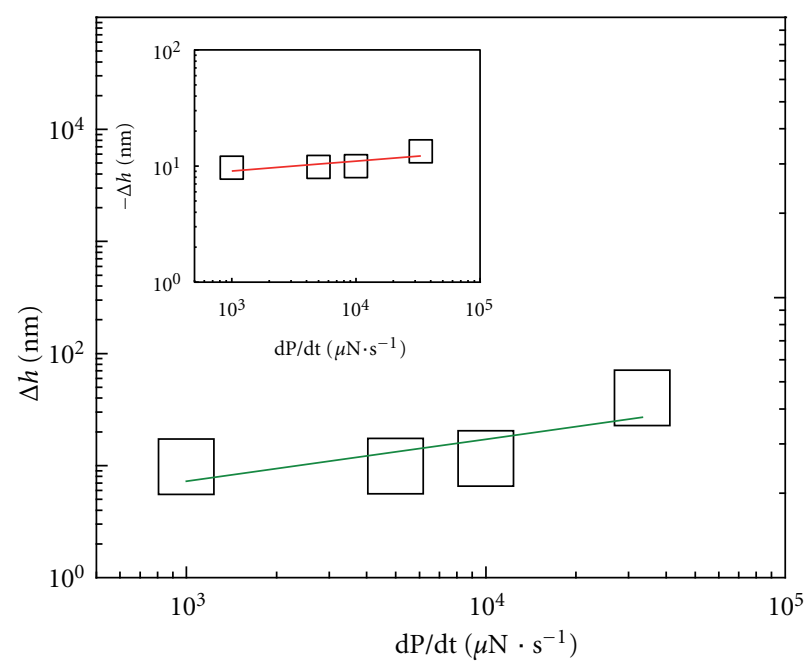

Figure 7: The dependencies of the depth increment $\left(\Delta h=h_{c 2}-h_{c 1}\right)$ and decrement $\left(-\Delta h=h_{c 1}-h_{c 2}\right.$ inset $)$ at which two consecutive nanoscale plasticity events say, 1 and 2 had occurred on the corresponding loading rates $(\mathrm{dP} / \mathrm{dt})$. The solid lines indicate the corresponding power law fits.

experiments. Similarly, the reduced depth $h^{\prime}\left(=h-h_{f}\right.$ where $h$ and $h_{f}$ represents the instantaneous and the final depth of penetrations obtained from the unloading cycle data) at all loading rates had empirical power law dependencies on the instantaneous nanoindentation load $(P)$, Figure 9.

The recent model [30] has also shown that if this power law dependence holds good then $h^{\prime}$ is related to $\dot{P}$ as: $h^{\prime} \propto$ $\dot{P}^{\beta}$ where $\beta$ is an empirical constant. Thus, the power law dependence of $(-\Delta h)$ on $\dot{P}$ (Figure 7) can be explained as mentioned above. 


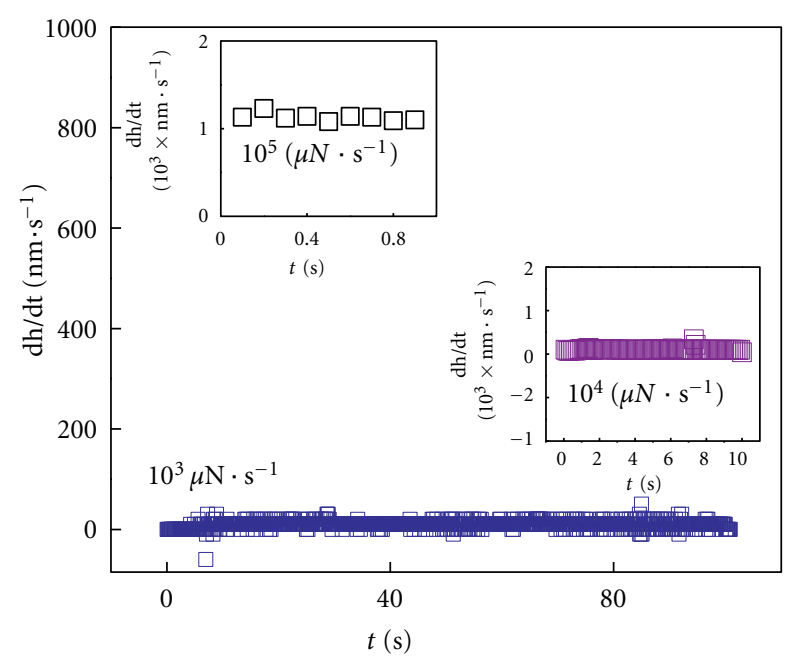

FIgURE 8: The minimal dependencies of $(\mathrm{dh} / \mathrm{dt})$ on time $(t)$ for the nanoindentation experiments conducted on tooth enamel at different loading rates of $10^{5}, 10^{4} \mu \mathrm{N} \cdot \mathrm{s}^{-1}$, and $10^{3} \mu \mathrm{N} \cdot \mathrm{s}^{-1}$.

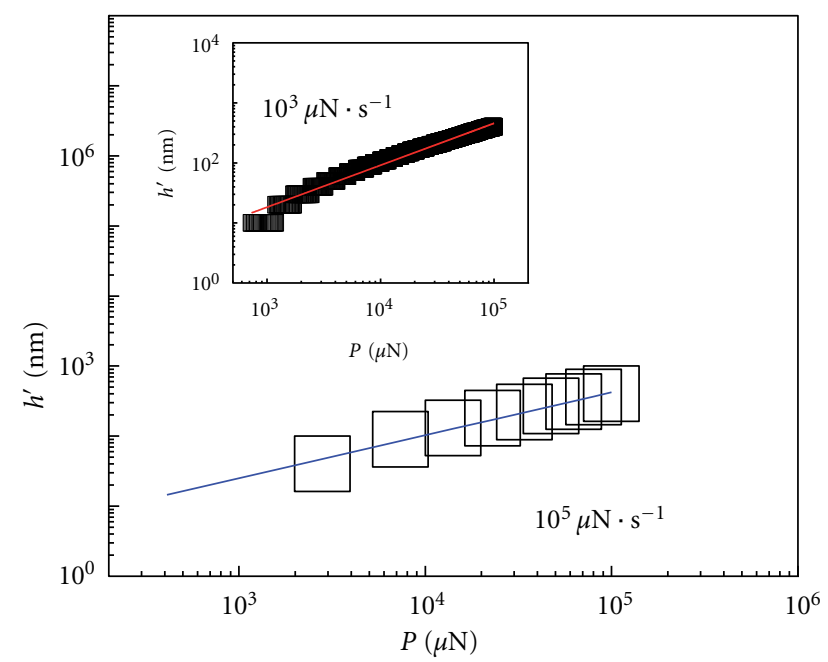

FIGURE 9: The experimental data on dependence of the instantaneous reduced nanoindentation depth $h^{\prime}$ on the instantaneous nanoindentation load $(P)$ obtained during the unloading cycles at $10^{5} \mu \mathrm{N} \cdot \mathrm{s}^{-1}$ and $10^{3} \mu \mathrm{N} \cdot \mathrm{s}^{-1}$ (inset of Figure 9) loading rates employed in the present work. The solid lines indicate the corresponding power law fits.

Now, we try to draw a plausible picture of the increase in nanoscale contact resistance with loading rate. Basically, the human tooth enamel can be considered from the deformation physics viewpoint as a macroscale-to-microscale-tonanoscale hybrid nanocomposite with a hierarchical architecture [1-3] as mentioned earlier. At the microscopic level it comprises of aligned prisms surrounded by an organic sheath. Here, the organic sheath plays the role of a protein matrix that is a biopolymer and hence is expected to deform in a viscoelastic manner [1].

At the nanoscale level, each prism contains numerous HAP crystal rods (Figure 3 ) of $\sim 50 \mathrm{~nm}$ diameter and oriented along the prism axis [3]. A nanometer-thin organic layer separates these rods [2]. Then, in response to the applied loading rate, the biopolymer matrix can shear to various extents to accommodate the strain due to the imposed deformation and in the process can also transfer the load among the adjacent mineral components. Therefore, it follows that at the nanoscale level then a sequential process of (a) repetitive loading, (b) load transfer, (c) unloading, and (d) subsequent loading process will happen during the penetration and withdrawal of the nanoindenter into and out of the enamel microstructure. It is proposed that this characteristic nanoscale deformation process gives rise to the observed pop-in effect in enamel nanoindentation.

In addition, there can be two additional factors which may contribute. For instance these are (i) the extent of local sharing of the total strain in between the protein matrix and the HAP crystal rods [31] and (ii) the process of stretching of individual biomolecules in the protein matrix all of which contribute in an additive fashion locally to the complete stretching of the protein matrix layer. We conjecture that at the lowest loading rate, this is what happens. Since the time of contact is more, the individual biomolecules in the protein matrix may get enough time to significantly stretch in response to the applied loading rate. But the biopolymers deform viscoelastically which comprises of both the elastic and anelastic components. Therefore, as the nanoindenter is withdrawn at the lower loading rates the individual biomolecules in the protein matrix will not get enough time to curl back completely to their original configuration. This is most likely to happen possibly due to the anelastic component of the deformation and more open structure of the biomolecules. As a result of this physical process, the overall elastic recovery becomes much lesser for the nanocomposite. Therefore, a smaller critical load $\left(P_{c}\right)$ is necessary at smaller loading rates to initiate the nanoscale plasticity events. However, at moderate and still higher loading rates (Figure 1) a completely different situation may arise. In such cases the time of contact was very small (e.g., $\sim 0.4$ second). As a consequence, the individual biomolecules in the protein matrix may get just enough time to at least moderately stretch in response to the applied loading rates. Under such situation then it becomes logical only to expect that they curl back to a relatively much higher extent (as compared to the case of lower loading rate) when the nanoindenter is withdrawn very quickly within for example, $\sim 0.4$ s during the unloading cycle.

Such a generic process will lead to a situation such that the overall elastic recovery becomes much higher for the nanocomposite at the higher loading rates. If this picture is correct, the nanoscale deformation of tooth enamel will give higher final depth of penetration at lower loading rate and lower final depth of penetration at higher loading rates. The experimental data (Figure 10) was completely in conformity with this conjecture and indeed showed an inverse power law dependence of the final depth of penetration on the loading rate. Therefore, it is obvious that at higher loading rates, a higher critical load $\left(P_{c}\right)$ will be needed to initiate the nanoscale plasticity events, as was indeed experimentally observed (Figure 2). 


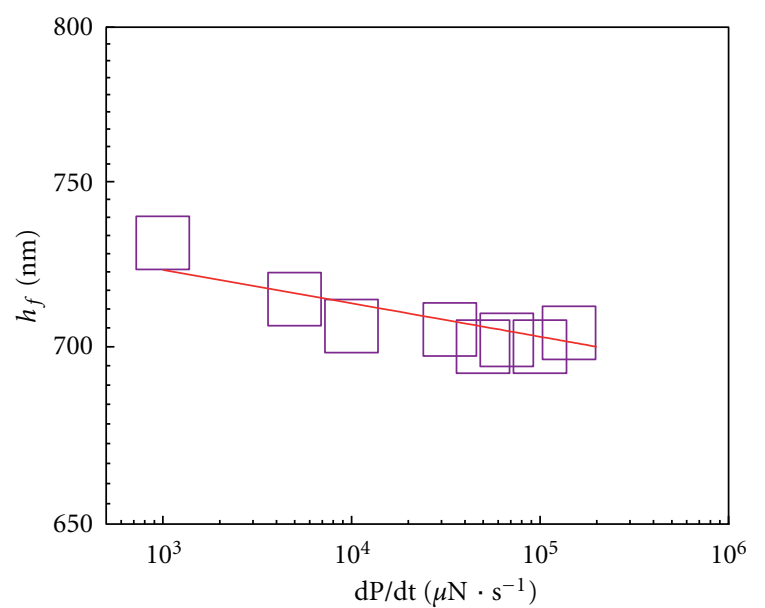

FIGURE 10: The dependence of the final depth of penetration $\left(h_{f}\right)$ on the loading rate $(\mathrm{dP} / \mathrm{dt})$. The solid line indicates the empirical inverse power law fit.

\section{Conclusions}

During nanoindentation experiments in human tooth enamel it was found that the critical load $\left(P_{c}\right)$ which signifies the materials intrinsic resistance against the initiation of incipient plasticity events at the nanoscale apparently increased with the applied loading rate. To the best of our knowledge, such experimental observation is the first. Based on the current experimental data it is suggested that the generic process responsible for such observation is the extent of elastic recovery or the lack of it in the biopolymeric matrix phase of the enamel nanocomposite in response to the lower and higher loading rates applied in the current nanoindentation experiments.

\section{Acknowledgments}

The authors are grateful to the Director, CSIR-Central Glass and Ceramic Research Institute (CGCRI), Kolkata for his kind permission to publish this paper. In addition, the authors appreciate the infrastructural supports received from all colleagues and particularly those received from the colleagues of the Mechanical Property Evaluation Section, NOCCD. Finally, the authors gratefully acknowledge the financial supports received from CSIR (Project no. NWP 0027).

\section{References}

[1] P. Y. Chen, A. Y. M. Lin, Y. S. Lin et al., "Structure and mechanical properties of selected biological materials," Journal of the Mechanical Behavior of Biomedical Materials, vol. 1, no. 3, pp. 208-226, 2008.

[2] M. A. Meyers, P. Y. Chen, A. Y. M. Lin, and Y. Seki, "Biological materials: structure and mechanical properties," Progress in Materials Science, vol. 53, no. 1, pp. 1-206, 2008.

[3] G. M. Luz and J. F. Mano, "Mineralized structures in nature: examples and inspirations for the design of new composite materials and biomaterials," Composites Science and Technology, vol. 70, no. 13, pp. 1777-1788, 2010.

[4] S. Marwan, A. Haiak, A. Trinkle, D. Garcia, and F. Yang, "Investigation of nanomechanical and tribological properties of dental materials," International Journal of Theoretical and Applied Multiscale Mechanics, vol. 1, no. 1, pp. 1-15, 2009.

[5] S. F. Ang, E. L. Bortel, M. V. Swain, A. Klocke, and G. A. Schneider, "Size-dependent elastic/inelastic behavior of enamel over millimeter and nanometer length scales," Biomaterials, vol. 31, no. 7, pp. 1955-1963, 2010.

[6] F. Lippert, D. M. Parker, and K. D. Jandt, "Susceptibility of deciduous and permanent enamel to dietary acid-induced erosion studied with atomic force microscopy nanoindentation," European Journal of Oral Sciences, vol. 112, no. 1, pp. 61-66, 2004.

[7] J. Ge, F. Z. Cui, X. M. Wang, and H. L. Feng, "Property variations in the prism and the organic sheath within enamel by nanoindentation," Biomaterials, vol. 26, no. 16, pp. 3333-3339, 2005.

[8] J. L. Cuy, A. B. Mann, K. J. Livi, M. F. Teaford, and T. P. Weihs, "Nanoindentation mapping of the mechanical properties of human molar tooth enamel," Archives of Oral Biology, vol. 47, no. 4, pp. 281-291, 2002.

[9] S. Poolthong, M. V. Swain, and T. Mori, "Mechanical properties of tooth following different storage conditions," Journal of Dental Materials, vol. 77, no. 5, pp. 1120-1136, 1998.

[10] S. Park, D. H. Wang, D. Zhang, E. Romberg, and D. Arola, "Mechanical properties of human enamel as a function of age and location in the tooth," Journal of Materials Science, vol. 19, no. 6, pp. 2317-2324, 2008.

[11] J. Zhou and L. L. Hsiung, "Depth-dependent mechanical properties of enamel by nanoindentation," Journal of Biomedical Materials Research Part A, vol. 81, no. 1, pp. 66-74, 2007.

[12] A. Zamiri and S. De, "Mechanical properties of hydroxyapatite single crystals from nanoindentation data," Journal of the Mechanical Behavior of Biomedical Materials, vol. 4, no. 2, pp. 146-152, 2011.

[13] W. C. Oliver and G. M. Pharr, "Improved technique for determining hardness and elastic modulus using load and displacement sensing indentation experiments," Journal of Materials Research, vol. 7, no. 6, pp. 1564-1580, 1992.

[14] A. Dey, R. Chakraborty, and A. K. Mukhopadhyay, "Nanoindentation of soda Lime-Silica glass: effect of loading rate," International Journal of Applied Glass Science, vol. 2, no. 2, pp. 144-155, 2011.

[15] C. A. Schuh, T. G. Nieh, and Y. Kawamura, "Rate dependence of serrated flow during nanoindentation of a bulk metallic glass," Journal of Materials Research, vol. 17, no. 7, pp. 1651-1654, 2002.

[16] Y. I. Golovin, V. I. Ivolgin, V. A. Khonik, K. Kitagawa, and A. I. Tyurin, "Serrated plastic flow during nanoindentation of a bulk metallic glass," Scripta Materialia, vol. 45, no. 8, pp. 947-952, 2001.

[17] C. A. Schuh and T. G. Nieh, "A nanoindentation study of serrated flow in bulk metallic glasses," Acta Materialia, vol. 51, no. 1, pp. 87-99, 2003.

[18] R. Nowak, T. Sekino, and K. Niihara, "Surface deformation of sapphire crystal," Philosophical Magazine A, vol. 74, no. 1, pp. 171-194, 1996.

[19] J. E. Bradby, S. O. Kucheyev, J. S. Williams et al., "Indentationinduced damage in GaN epilayers," Applied Physics Letters, vol. 80, no. 3, pp. 383-385, 2002. 
[20] S. O. Kucheyev, J. E. Bradby, J. S. Williams, C. Jagadish, and M. V. Swain, "Mechanical deformation of single-crystal ZnO," Applied Physics Letters, vol. 80, no. 6, pp. 956-958, 2002.

[21] R. Chakraborty, A. Dey, and A. K. Mukhopadhyay, "Loading rate effect on nanohardness of soda-lime-silica glass," Metallurgical and Materials Transactions A, vol. 41, no. 5, pp. 1301-1312, 2010.

[22] A. Dey, R. Chakraborty, and A. K. Mukhopadhyay, "Enhancement in nanohardness of soda-lime-silica glass," Journal of NonCrystalline Solids, vol. 357, no. 15, pp. 2934-2940, 2011.

[23] M. Bhattacharya, R. Chakraborty, A. Dey, A. K. Mukhopadhyay, and S. K. Biswas, "Effect of loading rate on nano-mechanical properties of Alumina," in Proceedings of the 3rd Workshop on Mechanical Behaviour of Systems at Small Length Scales, p. 40, Trivandrum, India, September 2011.

[24] S. Bhuniya, R. Chakraborty, A. Dey et al., "Effect of loading rate on microhardness of Alumina ceramics," in Proceedings of the International Conferenceon High Pressure Science and Technology (AIRAPT '11), p. 188, BARC, Mumbai, India, 2011.

[25] C. E. Packard and C. A. Schuh, "Initiation of shear bands near a stress concentration in metallic glass," Acta Materialia, vol. 55, no. 16, pp. 5348-5358, 2007.

[26] H. Shang, T. Rouxel, M. Buckley, and C. Bernard, "Viscoelastic behavior of a soda-lime-silica glass in the 293-833 K range by micro-indentation," Journal of Materials Research, vol. 21, no. 3, pp. 632-638, 2006.

[27] W. G. Mao, Y. G. Shen, and C. Lu, "Deformation behavior and mechanical properties of polycrystalline and single crystal alumina during nanoindentation," Scripta Materialia, vol. 65, no. 2, pp. 127-130, 2011.

[28] W. G. Mao, Y. G. Shen, and C. Lu, "Nanoscale elastic-plastic deformation and stress distributions of the $\mathrm{C}$ plane of sapphire single crystal during nanoindentation," Journal of the European Ceramic Society, vol. 31, no. 10, pp. 1865-1871, 2011.

[29] T. Ebisu and S. Horibe, "Analysis of the indentation size effect in brittle materials from nanoindentation load-displacement curve," Journal of the European Ceramic Society, vol. 30, no. 12, pp. 2419-2426, 2010.

[30] M. Bhattacharya, R. Chakraborty, A. Dey, A. K. Mandal, and A. K. Mukhopadhyay, "Improvement in nanoscale contact resistance of Alumina," Applied Physics A, vol. 107, no. 4, pp. 783-788, 2012.

[31] H. Gao, B. Ji, I. L. Jäger, E. Arzt, and P. Fratzl, "Materials become insensitive to flaws at nanoscale: lessons from nature," Proceedings of the National Academy of Sciences of the United States of America, vol. 100, no. 10, pp. 5597-5600, 2003. 

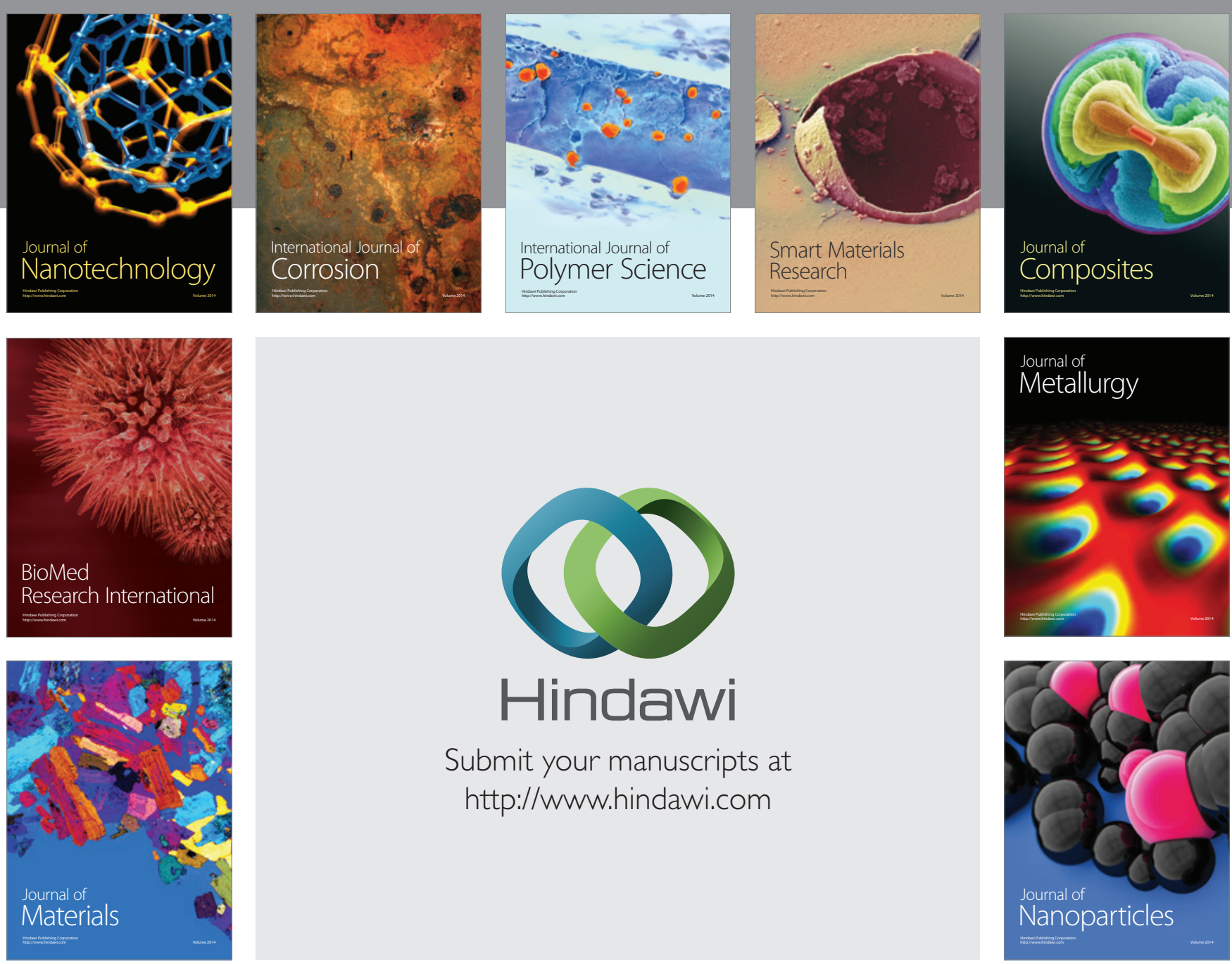

Submit your manuscripts at http://www.hindawi.com
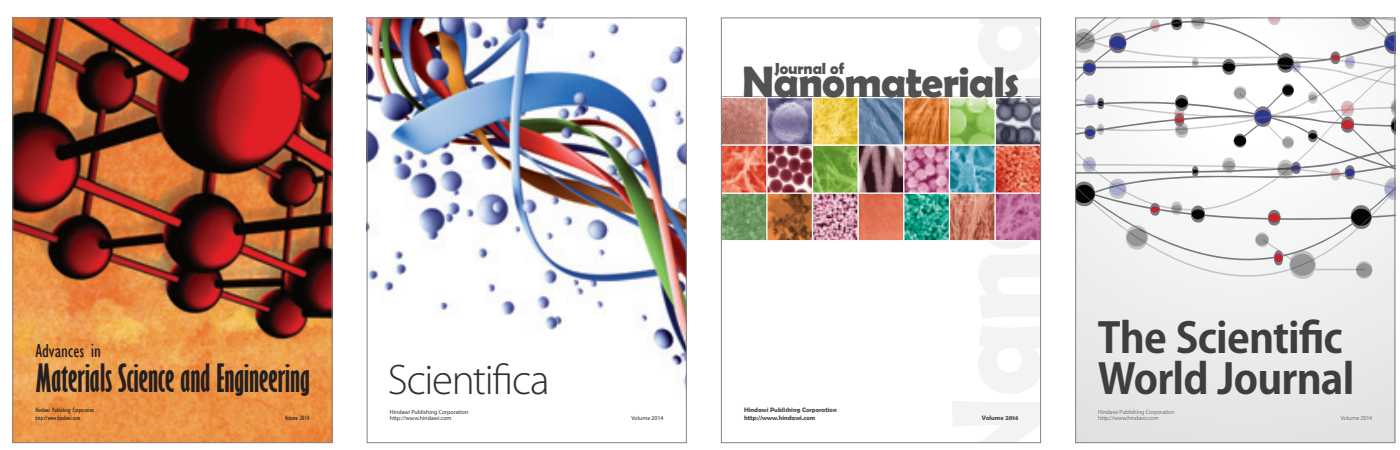

\section{The Scientific World Journal}
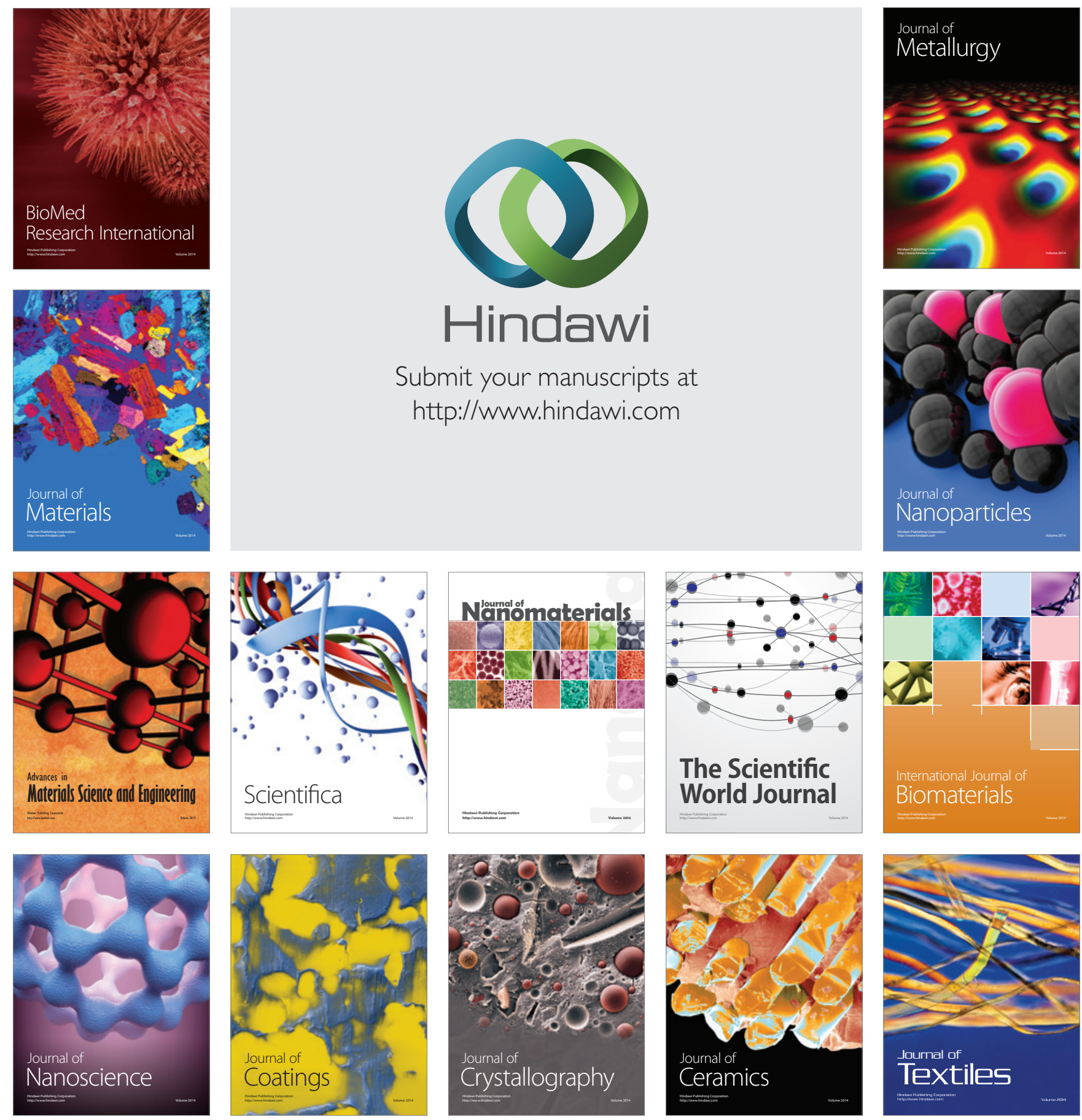